\title{
Periodicity and memory in mice
}

GWen Stephens, James L. Megaugh AND H. P. ALPERn

UNIVERSITY OF CALIFORNIA, IRVINE

Mice given ECS after training on an inhibitory avoidance task showed greater retrograde amnesia when training and treatments were given near the crest of the daily activity rhythm as measured by rectal temperature.

Evidence has accumulated in recent years that fluctuations in activity levels along the 24-h continuum are characteristic of many organs and organ systems (Halberg, 1960; Halberg, Albrecht, \& Bittner, 1959; Harner, 1961).

Several studies have indicated that a number of biologic variables may be related to learning and memory and to the response to amnesic agents such as electroconvulsive shock (ECS). An interaction between strain and phase of the activity cycle has been shown to influence maze learning performance in two strains of inbred mice (Hostetter, 1966). Thresholds to electroshock convulsions in rats were observed to be significantly lower at night than in the early afternoon (Woolley \& Timiras, 1962). Age (Tattan, 1957) and strain (Hudspeth, McGaugh, \& Thomson, 1964; Oliverio, McGaugh, \& Bovet, in preparation; Thompson \& Dean, 1955) have been shown to influence the degree of amnesia produced by electroconvulsive shock.

The preliminary experiments reported here were designed to investigate: (1) whether learning and memory in an inhibitory avoidance task in routine-standardized animals will vary with the rectal temperature rhythm, and (2) whether the amnesic effects of electroconvulsive shock following avoidance training will vary as a function of this rhythm.

\section{Subjects}

Swiss Webster male mice approximately 60 days of age were used as Ss. They were housed four animals per cage with ad lib food and water. Cages were kept on open shelves in a small quiet room lighted by a fluorescent ceiling fixture from $4 \mathrm{a} . \mathrm{m}$. to $4 \mathrm{p.m}$. and completely dark from 4 p.m. to 4 a.m. Room temperature was maintained at about $22^{\circ} \mathrm{C}$. Animals were taken from the colony room at least eight days prior to the experiments, and kept in this standardization room prior to and during the experimental period. The rectal temperature rhythm was spot checked with a Yellow Springs Telethermometer. In these animals, under these conditions, rectal temperature averaged $34.9 \pm .69^{\circ} \mathrm{C}$ at 1 p.m. and $36.5^{ \pm}$ $1.7^{\circ} \mathrm{C}$ at 9 p.m.

\section{Apparafus}

The apparatus for inhibitory aroidance training was that described by McGaugh \& Alpern (1966). The post- training electroshock consisted of a current of approximately $8 \mathrm{~mA}$ delivered for $.8 \mathrm{sec}$ by way of corneal electrodes. The animal was held in the E's hand during ECS administration. Resuscitation via the nose and mouth by means of a plastic bottle and tube was administered to all animals immediately after the shock.

\section{EXPERIMENT 1}

Seventy-two animals were divided into six groups of 12 animals each. Starting at 1 p.m. each animal of the first three groups was given three training trials in immediate succession on the inhibitory avoidance learning task. For each trial the mouse was placed on a small lighted metal platform in front of a hole leading into the darkened interior of a box. As the mouse stepped through the hole into the box he received a footshock of about $3 \mathrm{~mA}$. The mouse was removed from the box immediately and replaced on the platform. The removal and replacement took no more than 4 or 5 sec. This was repeated again. The animal was permitted to remain on the platform a maximum of 180 sec for each of the three training trials. The animals of the first group were given an electroshock as described above $1 \mathrm{~h}$ after the third training trial, the second group received an electroshock $3 \mathrm{~min}$ after the third training trial, and the animals of the third group were given a sham ECS $3 \mathrm{~min}$ after the third training trial. These training and electroshock stimulation procedures were repeated for the animals of Groups 4, 5, and 6 beginning at 9 p.m. that same evening. Each animal was retested at $24 \mathrm{~h}$ after its training-treatment session. The criterion on the retention test was $30 \mathrm{sec}$.

\section{EXPERIMENT 2}

One hundred twenty animals were divided into 10 groups of 12 each. The animals of Groups 1 and 2 received an electroshock at $1 \mathrm{~h}$ and at $3 \mathrm{~min}$, respectively, after the third training trial; those of Groups 3 and 4 were given electroshock immediately after the third training trial; and Group 5 received a sham ECS, as described above, immediately after the third training trial. These same operations, in this order, were repeated for the animals of Groups 6 through 10, respectively, starting at 9 p.m. that same night. Each animal was retested, as above, at $24 \mathrm{~h}$ after its training-treatment session.

Resulis

Acquisition and Retention. The results of the two experiments were comparable, consequently the data from both were pooled and analyzed together. In order to assess acquisition of the inhibitory aroidance task 


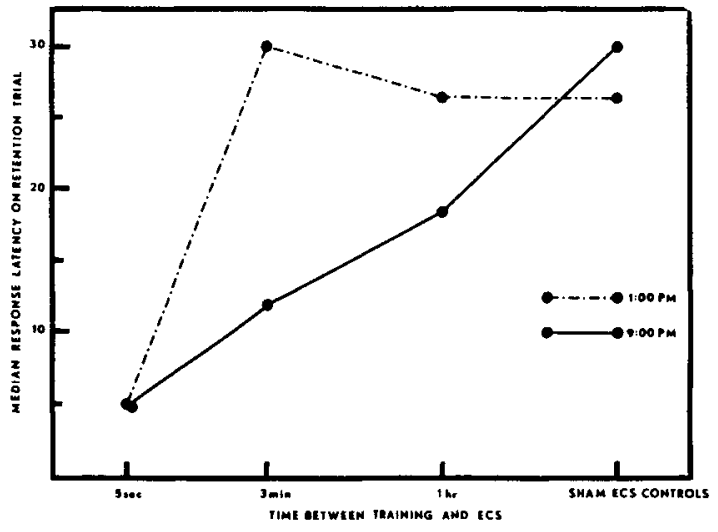

Fig. 1. Median retention latency of each treatment group, as a function of time between training and ECS.

as a function of the two training times, latencies on Trials 1, 2, and 3 for each animal were averaged for all of the groups at the 1 p.m. and the 9 p.m. training periods, respectively. The mean latencies for the 89 animals at 1 p.m. were $5.1 \mathrm{sec}$ for the first training trial, 9.0 sec for the second, and $21.2 \pm 3.4$ (S.E.) for the third. At 9 p.m. the mean latencies for the 93 animals were $4.6 \mathrm{sec}$ on the first, $6.9 \mathrm{sec}$ on the second, and $26.8 \pm 4.9$ (S.E.) sec on the third training trial. These differences were not significant.

An analysis of retention latencies as a function of total length of time spent by the animal on the training platform on the three training trials indicated that, for times over a total of $50 \mathrm{sec}$, the $30-\mathrm{sec}$ criterion was attained on retesting in almost all control animals. For this reason, in order to assess retention of the task in the controls at the two times of day, only those animals which had spent less than $50 \mathrm{sec}$ in the actual training situation were included. The mean retention latency of the 9 p.m. group $(N=20)$ was $21.9 \mathrm{sec}$; that of the 1 p.m. group $(\mathrm{N}=19)$ was $17.5 \mathrm{sec}$. This difference is significant $(p<.05)$.

Retrograde Amnesia. Figure 1 presents the median response latency on the 24-h retention trial for each group as a function of post-training treatment and time of day of training and treatment. At both times of the day there is a gradient of decreasing effectiveness of the electroshock in producing retrograde amnesia as a function of increasing time after the third training trial. However, the gradient is different for the two times of day. As is evident in Fig. 1, almost complete amnesia was produced in both of the immediate ECS groups. Day-night differences in retest latencies are significant (Mann-Whitney) for the $3 \mathrm{~min}$ ECS group ( $p<.005)$, but not for the other groups.

\section{Discussion}

This apparent correlation of better retention of an inhibitory avoidance task with the more active phase of the metabolic cycle as indicated by body temperature is reminiscent of the findings of Kleitman (1963), which correlated a number of performance variables with body temperature curve in the human.

Whatever the electrical and biochemical events underlying the time-dependent processes of acquisition and retention may be, the evidence from this study indicates that these processes, too, are more efficient at the active, rather than at the more quiescent, phase of the 24-h rhythm. But the more active tissue may be more susceptible to insult by a noxious agent. This could apply as well, apparently, to the amnesic effects of electroconvulsive shock.

ECS appears to produce greater amnesia when administered in the time region of an animal's crest of activity. This could mean either that memory consolidation rate varies inversely with metabolic activity or that susceptibility to ECS varies directly with metabolic activity. Whatever the basis, such variations must be considered in experimental investigations of memory storage processes.

\section{References}

Halberg, F. The 24-hour scale: a time dimension of adaptive functional organization. Perspect. Biol. Med., 1960, 3, 491-527.

Halberg, F., Albrecht, P. S., \& Bittner, J. J. Corticosterone rhythm of mouse adrenal in relation to serum corticosterone and handling. Amer. J. Physiol., 1959, 197, 1083-1085.

Harner, R. N. Electrocorticography and frequency analysis in mice; circadian periodicity in electrocerebral activity. EEG clin. Neurophysiol., 1961, 13, 752-761.

Hostetter, R. C. Time of day effects on learning and open field activity. Psychon. Sci., 1966, 5, 257-258.

Hudspeth, W. J., McGaugh, J. L., \& Thomson, C. W. Aversive and amnesic effects of electroconvulsive shock. J. comp. physiol. Psychol., 1964, 57, 61-64.

Kleitman, N. Sleep and wakefulness. Chicago and London: University Chicago Press, 1963. Pp. 131-1 5.

McGaugh, J. L., \& Alpern, H. P. Effects of electroshock on memory: amnesia without convulsions. Science, 1966, 152, 665-666.

Oliverio, A., McGaugh, J. L., \& Bovet, D. Strain differences in the emnesic effect of ECS. In preparation.

Tattan, J. V. Effects of electroshock convulsions on learning in rats as a function of age. J. comp. physiol. Psychol., 1957, 50, 405-407.

Thompson, R., \& Dean, W. A further study of the retroactive effect of ECS. J. comp. physiol. Psychol., 1955, 48, 488-491.

Wooley, D. E., \& Timiras, P. S. Estrous and circadian periodicity and electroshock convulsions in rats. Amer. J. Physiol., 1962, $202,379-382$.

\section{Note}

1. This research was supported by Research Grants MH 10261-03 and $\mathrm{MH}$ 12526-01 from the National Institutes of Mental Health, United States Public Heal th Service. 